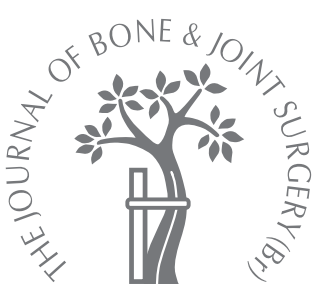

D. J. Langton,

S. S. Jameson,

T. J. Joyce,

J. Webb,

A. V. F. Nargol

From the University

Hospital of North

Tees, Stockton-on-

Tees, England

\title{
The effect of component size and orientation on the concentrations of metal ions after resurfacing arthroplasty of the hip
}

Increased concentrations of metal ions after metal-on-metal resurfacing arthroplasty of the hip remain a concern. Although there has been no proven link to long-term health problems or early prosthetic failure, variables associated with high metal ion concentrations should be identified and, if possible, corrected. Our study provides data on metal ion levels from a series of 76 consecutive patients ( 76 hips) after resurfacing arthroplasty with the Articular Surface Replacement. Chromium and cobalt ion concentrations in the whole blood of patients with smaller ( $\leq \mathbf{5 1} \mathbf{~ m m}$ ) femoral components were significantly higher than in those with the larger $(\geq 53 \mathrm{~mm})$ components $(p<0.01)$. Ion concentrations in the former group were significantly related to the inclination $(p=0.01)$ and anteversion $(p=0.01)$ of the acetabular component. The same relationships were not significant in the patients with larger femoral components ( $p=0.61$ and $p=0.49$, respectively). Accurate positioning of the acetabular component intra-operatively is essential in order to reduce the concentration of metal ions in the blood after hip resurfacing arthroplasty with the Articular Surface Replacement implant.

The use of metal-on-metal hip resurfacing arthroplasty continues to grow despite concerns about the potential consequences of chronic exposure to metal ions. ${ }^{1}$ Currently, there is no firm evidence to suggest that there is an accumulation of metal particles or an increased risk of systemic or end-organ disease in patients with metal implants. ${ }^{2-4}$ However, the potential of metal-on-metal arthroplasty to trigger mutations leading to increased susceptibility to malignant transformation has been suggested. ${ }^{5}$ Pre-malignant changes in the bone marrow adjacent to total hip replacement (THR) implants have been reported. ${ }^{6-8}$ Further concerns include the possibility of delayed-type hypersensitivity reactions ${ }^{9,10}$ and teratogenicity. ${ }^{11}$

It is likely that the systemic concentrations of metal ions are directly related to the rate of wear of the components. To date, results from tribological studies have proposed that wear rates could be reduced by decreasing the clearance and surface roughness, and by increasing the sphericity and carbon content of the components. ${ }^{12-17}$ An experimental study has suggested that larger components are more likely to produce a thicker fluid film between the articular surfaces. ${ }^{14}$ They also provide larger surface areas over which contact stresses are distributed. ${ }^{18}$
A meaningful comparison of the results reported so far is difficult because of the different types of sample and analytical methods used. Daniel et $\mathrm{al}^{19}$ concluded that measurements in whole blood samples using inductively-coupled plasma mass spectrometry were more sensitive than those obtained from serum samples using graphite furnace atomic absorption spectrometry. The former has the ability to overcome any interference caused by the complex matrix in whole blood, ${ }^{20}$ making it a more reliable method for measuring levels of metal ions. The concentrations of metal ions in serum samples, measured with graphite furnace atomic absorption spectrometry, may fall outside the limits of detection, with values often assigned arbitrary figures. ${ }^{21}$

Furthermore, analysis of serum is not sensitive enough to detect placental transmission of metal ions. ${ }^{22}$ This type of transmission has been proven to occur when high-resolution inductively-coupled plasma-mass spectromentry was used to analyse whole blood samples. $^{11}$

The process leading to the release of metal ions into the systemic circulation is complex, and is thought to be determined by patientrelated, surgical technique-related and implantspecific variables. Rim contact, impingement, acetabular component deformation, point 
Table I. Clinical details, radiological measurements and outcome data in the 76 patients

\begin{tabular}{|c|c|}
\hline & Number \\
\hline Mean age in years (range) & $55 \quad(35$ to 74$)$ \\
\hline Male:female & 49:27 \\
\hline Mean follow-up in months (range) & $26 \quad(13$ to 44$)$ \\
\hline Mean body mass index in $\mathrm{kg} / \mathrm{m}^{2}$ (range) & $26 \quad$ (19 to 32$)$ \\
\hline Mean ASA* score (range) & 1.6 (1 to 3$)$ \\
\hline Number of Charnley grade A patients (\%) & $48 \quad(63)$ \\
\hline Number with osteoarthritis (\%) & $49 \quad(64)$ \\
\hline Median diameter of femoral component in mm (range) & $49 \quad$ (41 to 59$)$ \\
\hline Mean inclination angle in ${ }^{\circ}$ of acetabular component (range) & 48.5 (32 to 62$)$ \\
\hline $\begin{array}{l}\text { Mean anteversion angle of the acetabular component in degrees } \\
\text { (range) }\end{array}$ & 19.8 (7 to 37$)$ \\
\hline Mean stem-neck angle in degrees (range) & $8.5(-8$ to 28$)$ \\
\hline \multicolumn{2}{|l|}{ Mean outcome scores (range) } \\
\hline Harris hip score & $94 \quad(35$ to 100$)$ \\
\hline UCLA $^{\dagger}$ activity score & $7.4(3$ to 10$)$ \\
\hline \multicolumn{2}{|l|}{ Median serum metal ion levels in $\mu \mathrm{g} / \mathrm{l}$ (range) } \\
\hline Chromium & $3.61(0.6$ to 115.0$)$ \\
\hline Cobalt & 1.89 (0.4 to 228.0$)$ \\
\hline \multicolumn{2}{|l|}{ Median whole blood metal ion levels in $\mu \mathrm{g} / \mathrm{l}$ (range) } \\
\hline Chromium & $3.42(1.5$ to 69.8$)$ \\
\hline Cobalt & $1.99(0.4$ to 271.0$)$ \\
\hline
\end{tabular}

loading, sliding distance and the thickness of the lubricating fluid film can all influence the extent of a metal ion generation. ${ }^{23}$ We believe that the alignment of both the femoral and acetabular components is critical to this process. We expect larger implants to have improved wear characteristics and to be associated with reduced systemic ion concentrations because of improved fluid-film lubrication.

We have therefore analysed the effect of these variables in a large series of consecutive patients with a wide range of sizes of the femoral component.

\section{Patients and Methods}

Between April 2004 and August 2006, the senior author (AVFN) performed the first consecutive series of hip resurfacing arthroplasties using the Articular Surface Replacement (ASR; DePuy International Ltd, Leeds, United Kingdom). These patients were enrolled in a prospective, single-surgeon, independent study. Informed consent was obtained from the patients at the time of their operations. All the patients agreed to long-term clinical and radiological follow-up and to post-operative measurement of metal ion levels in whole blood. Specific exclusion criteria were bilateral resurfacing arthroplasties and other metal implants at the time of blood sampling. Patients with abnormal serum urea/creatinine concentrations were not considered for hip resurfacing, since impaired renal function can result in dramatically elevated serum chromiun $(\mathrm{Cr})$ and Co concentrations. ${ }^{24}$ Blood samples were obtained at more than 12 months after operation when the implants were anticipated to have passed the 'bedding-in' phase and, theoretically, had reached a steady-state wear. ${ }^{25,26}$ This series represents the first 76 patients to meet the above criteria. Their clinical details are summarised in Table I. The mean follow-up was 26 months (13 to 44).

The ASR prosthesis. The femoral and acetabular components are made of cast high-carbon-Cr-Co-alloy. The surface roughness $(\mathrm{Ra})$ should be no greater than $0.05 \mu \mathrm{m}$, the deviation from full sphericity less than $10 \mu \mathrm{m}$ and the radial clearance less than $10 \mu \mathrm{m}$ (manufacturer's data; DePuy International). The prosthesis is intended for hybrid fixation, with a cemented femoral component and a press-fit cementless acetabular component with an external porous coating (Porocoat, Depuy, Warsaw, Indiana) with a volume of porosity of between $40 \%$ and $50 \%$. The acetabular component subtends less than a hemisphere to allow for shallower seating and potential preservation of acetabular bone stock. The design of the implant and the surgical technique (posterior surgical approach) did not change throughout the study period. The median diameter of the femoral components used was $46 \mathrm{~mm}$ in women and $51 \mathrm{~mm}$ in men (41 to 59).

Metal ion sampling and analysis. Venous cannulation was performed with a 21-gauge stainless-steel needle (Venflon, Becton Dickinson, Helsingborg, Sweden), with disposal of the first $5 \mathrm{ml}$ of blood to avoid contamination. All samples were frozen and sent for blinded trace-element analysis to the Biochemistry Department of the Royal Surrey County Hospital, Guildford, United Kingdom. 


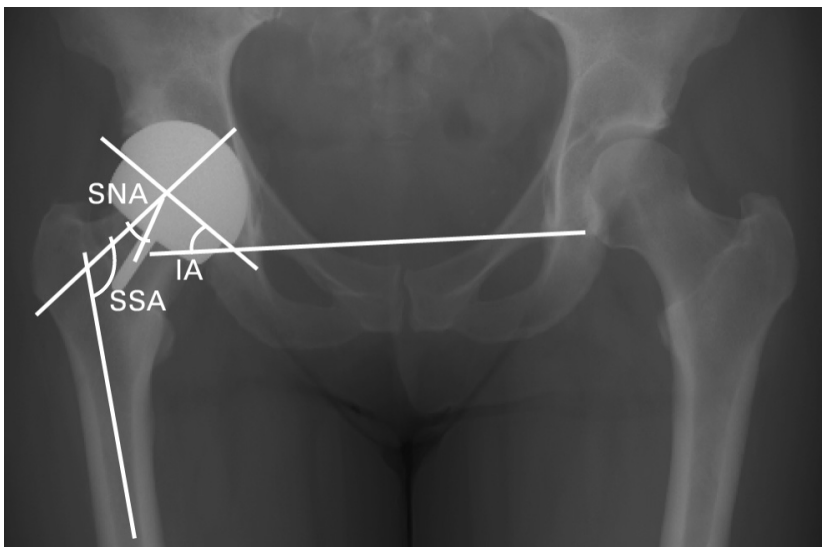

Fig. 1

Post-operative radiograph showing the measurements performed (IA, inclination angle; SNA, stem-neck angle; SSA, stem-shaft angle).

The concentrations of $\mathrm{Cr}$ and Co in serum, whole blood and erythrocytes were measured using inductively-coupled mass spectrometry.

The measured isotopes were ${ }^{52} \mathrm{Cr}$ and ${ }^{59} \mathrm{Co}$. Collision cell mode, using $7 \%$ hydrogen in helium, was adopted to eliminate isotopic interferences. Blood samples were diluted 50 -fold in $1 \% \mathrm{v} / \mathrm{v}$ nitric acid containing germanium as an internal standard. The analysis was calibrated using matrix-matched standard solutions prepared in horse blood. A series of reference materials was analysed within the same analytical run to demonstrate the accuracy of the results. The concentrations of metal ions was expressed as micrograms per litre $(\mu \mathrm{g} / \mathrm{l})$.

Radiological measurements. These were obtained from digital post-operative standing anteroposterior pelvic radiographs, with the patients in their natural weightbearing position. Care was taken to minimise pelvic malrotation. The AGFA IMPAX ES Web 1000 version 5.1 (AgfaGevaert Group, Mortsel, Belgium) and Einzel-Bild-Roentgen-Analyse (EBRA, University of Innsbruck, Innsbruck, Austria) software were used for analysis. All the angles described were radiological. These may have differed from anatomical angles and angles measured intra-operatively. ${ }^{27}$ All the radiological measurements were performed by two of the authors (DJL and SSJ) and the mean values were used. They preceded the metal ion analyses. The following measurements were made (Fig. 1):

Inclination of the acetabular component. The ASR acetabular component has an obvious change in contour at the outermost limits of the convex surface. The superolateral and inferomedial apices were identified and joined. This line was extended inferiorly to subtend an angle with the inter-teardrop line. Plain radiography has been shown to be a reliable method of measuring the inclination of acetabular components. $^{28}$ Measurements performed using IMPAX software were compared with those obtained with EBRA.
Acetabular version. This was analysed using EBRA software, a method previously validated in the literature. ${ }^{29,30}$ The stem-shaft angle. In order to determine the angle at which the femoral component was positioned, relative to the femoral shaft in the coronal plane, a line was drawn perpendicular to the base of the component. The angle subtended by this line and the anatomical axis of the proximal femur was defined as the stem-shaft angle. This was preferred to measurements using the prosthetic stem as a reference because the ASR stem has a tapered configuration.

Stem-neck alignment. This was calculated by subtracting the pre-operative femoral neck-shaft angle from the stemshaft angle. The resulting figures were assigned positive values when the femoral component was aligned in relative valgus, and negative values if aligned in relative varus.

Statistical analysis. The results were analysed using Spearman's correlation analysis by calculating the correlation coefficient $(r)$ between the independent variables (radiological measurements, gender, age, the duration of followup, the University of California, Los Angeles (UCLA) activity score ${ }^{31}$ at most recent follow-up and the dependent variables ( $\mathrm{Cr}$ and $\mathrm{Co}$ concentrations)). Statistical significance was defined as $\mathrm{p} \leq 0.05$. Once statistically-significant correlations had been identified, the respective variables were put forward for multiple linear regression analysis. Statistical analysis was carried out using SPSS version 16.0 (SPSS Inc., Chicago, Illinois).

\section{Results}

The concentration of metal ions in whole blood is regarded as the most accurate representation of systemic exposure to metal. ${ }^{11,25}$ Serum and whole blood concentrations were found to correlate well with each other for both $\mathrm{Cr}$ and $\mathrm{Co}$ ( $\mathrm{r}=0.917, \mathrm{p}<0.001, \mathrm{r}=0.851, \mathrm{p}<0.001, \mathrm{r}=0.890$, $\mathrm{p}<0.001$ and $\mathrm{r}=0.965, \mathrm{p}<0.001$, respectively; Table II). Thus, we used the whole blood ion concentrations throughout the study. The concentration of $\mathrm{Cr}$ in whole blood strongly correlated with that of Co $(\mathrm{r}=0.890, \mathrm{p}<0.001)$. For convenience, therefore, the results for $\mathrm{Cr}$ were used in the graphical analyses.

One female patient had revision at 14 months postoperatively because of aseptic loosening. Her whole blood $\mathrm{Cr}$ and Co concentrations immediately before revision were $5.25 \mu \mathrm{g} / \mathrm{l}$ and $7.82 \mu \mathrm{g} / \mathrm{l}$, respectively. No other patient in the series has undergone or is awaiting revision.

Reliability of measurements. Measurements of the acetabular component using EBRA showed a mean inter-observer difference of $1.4^{\circ}$ (maximum $7.6^{\circ}$, SD 2.6). For the inclination angle, the mean inter-observer error was $0.2^{\circ}$ (maximum $2.4^{\circ}$, SD 1.3) using EBRA, and $0.4^{\circ}$ (maximum $6.8^{\circ}$, SD 2.4) using the standard radiological method (IMPAX). Measurements of the inclination angle performed with the IMPAX software showed a mean difference of $0.6^{\circ}$ (maximum $8.8^{\circ}$, SD 2.4) compared with those obtained using EBRA.

A Bland-Altman plot of these results showed adequate inter-observer reliability. In addition, sufficient reliability 
Table II. Results of analysis, using whole blood Chromium ( $\mathrm{Cr}$ ) and Cobalt (Co) levels as the dependent variables

\begin{tabular}{lllll}
\hline & \multicolumn{2}{l}{ Whole blood Cr levels } & & \multicolumn{2}{l}{ Whole blood Co levels } \\
\cline { 2 - 3 } Independent variable & Correlation coefficient $(\mathbf{r})$ & p-value & & Correlation coefficient (r) p-value \\
\hline Age & -0.184 & 0.190 & -0.105 & 0.362 \\
BMI & 0.089 & 0.517 & 0.100 & 0.468 \\
ASA score & -0.056 & 0.676 & 0.020 & 0.884 \\
Duration of follow-up & 0.024 & 0.838 & 0.113 & 0.326 \\
Diameter of femoral component & -0.307 & 0.007 & -0.306 & 0.008 \\
Inclination of acetabular component & 0.297 & 0.011 & 0.399 & $<0.001$ \\
Anteversion of acetabular component & 0.132 & 0.258 & 0.177 & 0.131 \\
Stem-neck angle & -0.159 & 0.234 & -0.233 & 0.081 \\
Whole blood Co level & 0.890 & $<0.001$ & -0.207 & 0.09 \\
Serum Co level & 0.851 & $<0.001$ & 0.965 & $<0.001$ \\
Serum Cr level & 0.917 & $<0.001$ & -0.254 & 0.057 \\
\hline
\end{tabular}

* BMI, body mass index; ASA, American Society of Anesthesiologists
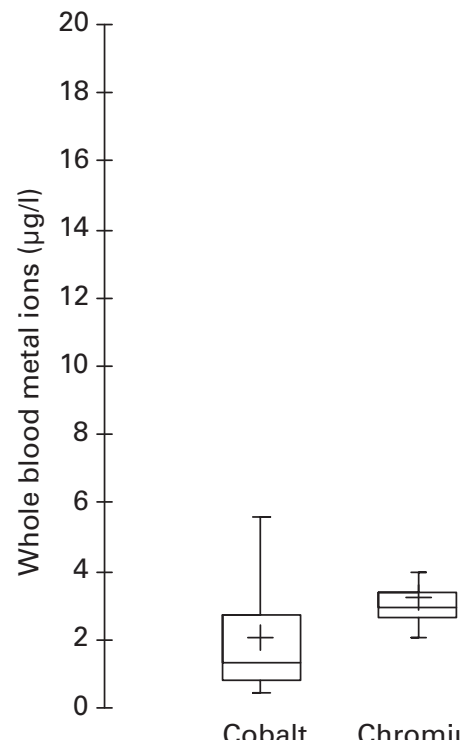

Cobalt

Chromium

Large implants

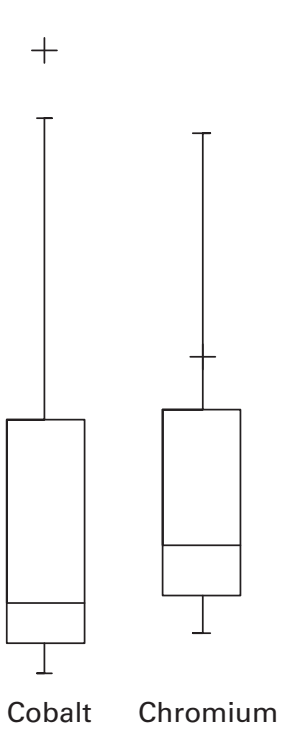

Small implants

Fig. 2

Box plot showing the range of blood metal ion concentrations associated with the large $(\leq 53 \mathrm{~mm})$ and small $(\geq 51 \mathrm{~mm})$ femoral implants. Statistical outliers have been omitted for ease of graphical representation. Box lengths represent the interquartile range, the horizontal lines within the boxes the median value, and + mean.

was found between the two techniques for measurement of the inclination angle with regard to the clinical implications. Throughout the text therefore our results are presented using the mean of the two observers (DJL, SSJ) measurements obtained with EBRA.

Size of the femoral component. In 21 patients, a femoral component larger than $51 \mathrm{~mm}$ in diameter was used. The remaining 55 patients received implants with diameters of between $41 \mathrm{~mm}$ and $51 \mathrm{~mm}$. Correlational analysis did not establish a significant relationship between femoral

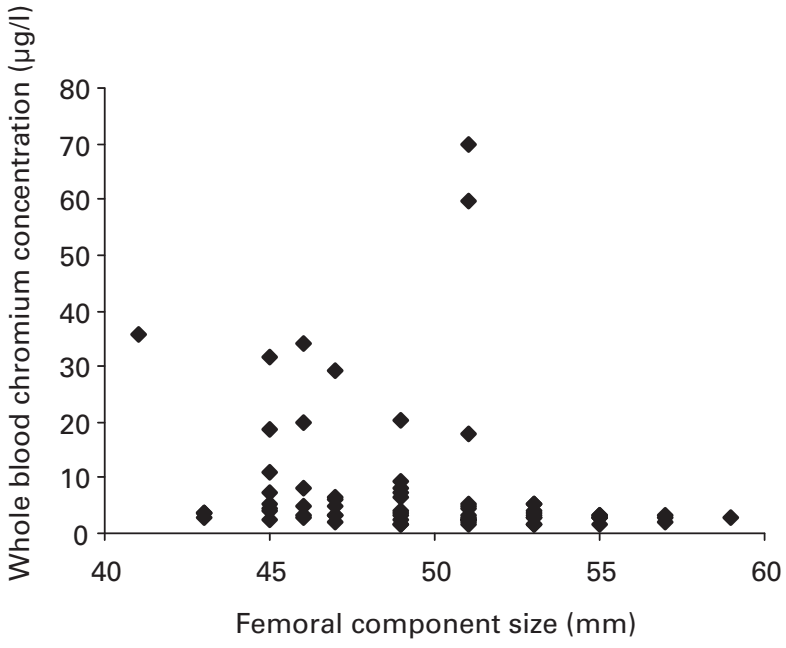

Fig. 3

Scatter plot of the size of the femoral head versus whole blood chromium ion concentrations for the 76 patients.

size and blood metal ion concentrations. However, excessively high values were obtained from two patients with femoral components of $51 \mathrm{~mm}$. It is not clear whether these values represented a threshold value of the diameter of the femoral components above which metal ion concentrations tended to be low. With these values treated as statistical outliers, femoral size showed an inverse relationship to $\mathrm{Cr}(\mathrm{r}=-0.328, \mathrm{p}=0.004)$ and $\mathrm{Co}(\mathrm{r}=-0.315$, $p=0.006)$ concentrations. As Figures 2 and 3 show, all patients who received a 'large' $(\geq 53 \mathrm{~mm})$ femoral implant had lower concentrations of metal ions, compared with those with a 'small' ( $\leq 51 \mathrm{~mm}$ ) femoral implant. A MannWhitney $\mathrm{U}$ test showed that there was a significant difference in the concentrations of both Cr (large 1.9, small 9.8; $\mathrm{p}=0.007$ ) and Co (large 3.0, small 18.1; $\mathrm{p}=0.004$ ) in these two groups. 
Table III. Spearman's rank order correlaton coefficent of chromium ion levels in whole blood with various clinical and radiological parameters in patients with small $(\leq 51 \mathrm{~mm})$ and large $(\geq 53 \mathrm{~mm})$ femoral implants

\begin{tabular}{|c|c|c|c|c|}
\hline \multirow[b]{2}{*}{ Independent variable ${ }^{*}$} & \multicolumn{2}{|l|}{ Small $(\leq \mathbf{5 1} \mathbf{m m})$} & \multicolumn{2}{|l|}{ Large ( $\geq 53 \mathbf{m m}$ ) } \\
\hline & Correlation coefficient ( $r$ ) & p-value & Correlation coefficient ( $r$ ) & p-value \\
\hline Age & -0.184 & 0.190 & -0.119 & 0.628 \\
\hline BMI & 0.089 & 0.517 & 0.053 & 0.920 \\
\hline Duration of follow-up & 0.024 & 0.838 & -0.180 & 0.314 \\
\hline Diameter of femoral component & -0.189 & 0.844 & -0.264 & 0.294 \\
\hline Inclination of acetabular component & 0.372 & 0.011 & 0.088 & 0.610 \\
\hline Anteversion of acetabular component & 0.326 & 0.010 & -0.148 & 0.489 \\
\hline Stem-neck angle & -0.206 & 0.631 & -0.050 & 0.993 \\
\hline Stem-shaft angle & -0.011 & 0.764 & -0.163 & 0.701 \\
\hline UCLA score at final follow-up activity score & -0.190 & 0.844 & -0.361 & 0.154 \\
\hline
\end{tabular}

* BMI, body mass index; UCLA, University of California, Los Angeles

Table IV. Comparison of clinical data, radiological measurements and metal ion levels in whole blood in patients with small $(\leq 51 \mathrm{~mm})$ and large $(\geq 53 \mathrm{~mm})$ femoral implants

\begin{tabular}{|c|c|c|c|}
\hline & Small $(\leq \mathbf{5 1} \mathbf{~ m m})$ & Large ( $\geq 53 \mathbf{~ m m})$ & p-value \\
\hline Number of patients & 55 & 21 & \\
\hline Male:female & $28: 27$ & 21:0 & $<0.001^{*}$ \\
\hline Mean age in years (range) & 57.6 (35 to 68$)$ & 54.5 (42 to 74$)$ & $0.149^{\dagger}$ \\
\hline Mean duration of follow-up in months (range) & 26 (13 to 43$)$ & $26(13$ to 41$)$ & $0.995^{\ddagger}$ \\
\hline Mean inclination of acetabular component in ${ }^{\circ}$ (range) & 48.9 (32 to 61$)$ & 49.2 (36 to 62$)$ & $0.604^{\dagger}$ \\
\hline Mean anteversion of acetabular component in ${ }^{\circ}$ (range) & $20.2(17.6$ to 23$)$ & $18.8(9.9$ to 31.2$)$ & $0.454^{\dagger}$ \\
\hline Median whole blood concentration of $\mathrm{Cr}$ (range) & $4.12(1.5$ to 69.8$)$ & $3.04(1.5$ to 5.5$)$ & $0.004^{\ddagger}$ \\
\hline Median concentration of Co (range) & $2.43(0.48$ to 271$)$ & $1.48(0.4$ to 5.6$)$ & $0.007^{\ddagger}$ \\
\hline
\end{tabular}

* Fisher's exact test

† independent samples $t$-test

¥ Mann-Whitney U test

Table V. Comparison of clinical data, radiological measurements and metal ion levels in whole blood in men and women with small $(\leq 51 \mathrm{~mm})$ femoral components

\begin{tabular}{llll}
\hline & Men & Women & p-value \\
\hline Number of patients & 28 & 27 & $53(36$ to 64$)$ \\
Mean age in years (range) & $56(35$ to 68$)$ & $18(13$ to 41$)$ \\
Mean duration of follow-up in months (range) & $29(14$ to 43$)$ & $49.1(32$ to 61$)$ \\
Mean inclination of acetabular component $\left(^{\circ}\right)($ range) & $47.4(39$ to 60$)$ & $23.0(7$ to 37$)$ \\
Mean anteversion of acetabular component $\left({ }^{\circ}\right)($ range) & $17.6(8$ to 31$)$ & $45(41$ to 51$)$ \\
Mean diameter of the femoral component in mm (range) & $49(47$ to 51$)$ & $4.51(2.29$ to 35.9$)$ & $0.005^{\dagger}$ \\
Median whole blood concentration of Cr (range) & $3.25(1.5$ to 69.8$)$ & $3.54(0.48$ to 155$)$ \\
Median concentration of Co (range) & $1.71(0.59$ to 271$)$ & $0.005^{*}$ \\
\hline
\end{tabular}

* independent samples $t$-test

$\dagger$ Mann-Whitney U test

The metal ion concentrations in the blood of patients with large femoral implants showed no significant correlation with any of the variables investigated (Table III). All other significant variables between the two groups were comparable except for the gender discrepancy (Table IV). For the purposes of further presentation and analysis of data, the groups remained separated.

Patients with a small femoral component. There were 28 men and 27 women who received femoral implants with a diameter of $\leq 51 \mathrm{~mm}$. In men the median diameter of the femoral component was $49 \mathrm{~mm}$ (47 to 59 ) and in women it was $45 \mathrm{~mm}$ (41 to 51) (Mann-Whitney U test, $\mathrm{p}<0.001$ ). In the men and women of the small head group, significant differences were found between the mean femoral component size, angle of anteversion and time to follow-up. (Table V). Ion concentrations in the blood of these patients correlated significantly with acetabular inclination and anteversion (Table III).

Acetabular inclination. There was a positive correlation between the inclination of the acetabular component and the concentrations of Co $(\mathrm{r}=0.439, \mathrm{p}<0.001)$ and $\mathrm{Cr}(\mathrm{r}=0.372, \mathrm{p}=0.011)$. This relationship was main- 


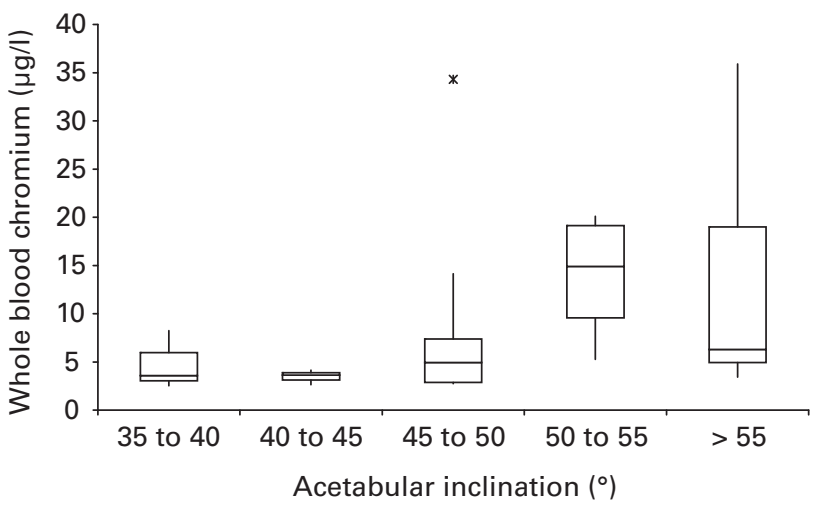

Fig. 4

Box plot showing the inclination angle of the femoral component versus chromium level for 27 female patients with femoral components $\leq 51 \mathrm{~mm}$. Outliers are represented by '*'.

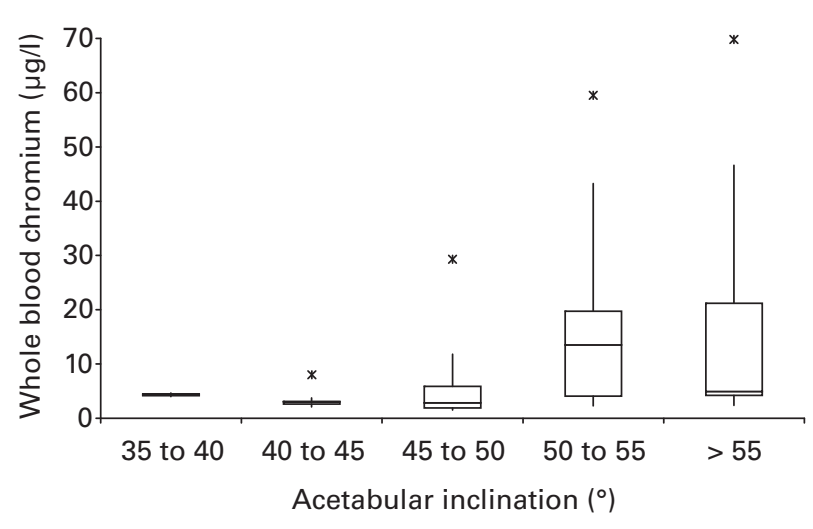

Fig. 5

Box plot showing the inclination angle of the acetabular component versus chromium levels for 28 male patients with femoral components $\leq 51 \mathrm{~mm}$.

tained when the genders were analysed separately (Figs 4 and 5). Figure 6 shows the non-significant relationship between the inclination of the cup and $\mathrm{Cr}$ ion levels in the patients with large implants, demonstrating the distinctly different behaviour between implants of small and large diameter.

Acetabular anteversion. There was a positive correlation between the anteversion of the acetabular component and the concentrations of $\mathrm{Cr}(\mathrm{r}=0.330, \mathrm{p}=0.01)$ and $\mathrm{Co}$ $(\mathrm{r}=0.338, \mathrm{p}=0.008)$ in whole blood (Fig. 7). These findings should be interpreted with caution, because anteversion of the acetabular components also correlated positively with inclination $(\mathrm{r}=0.290, \mathrm{p}=0.018)$.

Multifactorial analysis. The inclination and anteversion angles of the acetabular components were included in a multiple linear regression analysis model involving all patients. The correlation coefficient was $0.15(\mathrm{p}=0.05)$.

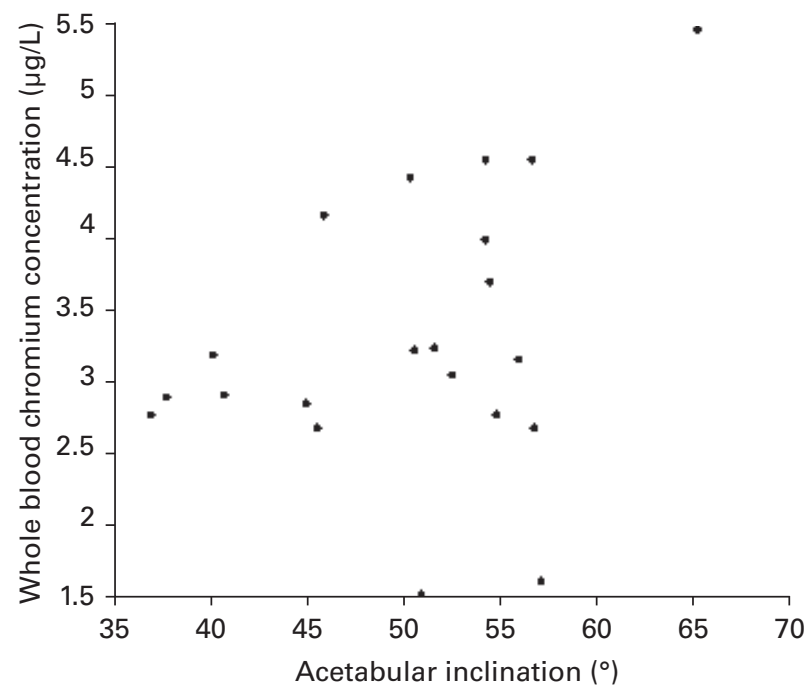

Fig. 6

Scatter plot showing the lack of correlation between the level of chromium ions in whole blood and the inclination angle of the acetabular component in 21 patients with femoral components $\geq 53 \mathrm{~mm}$.

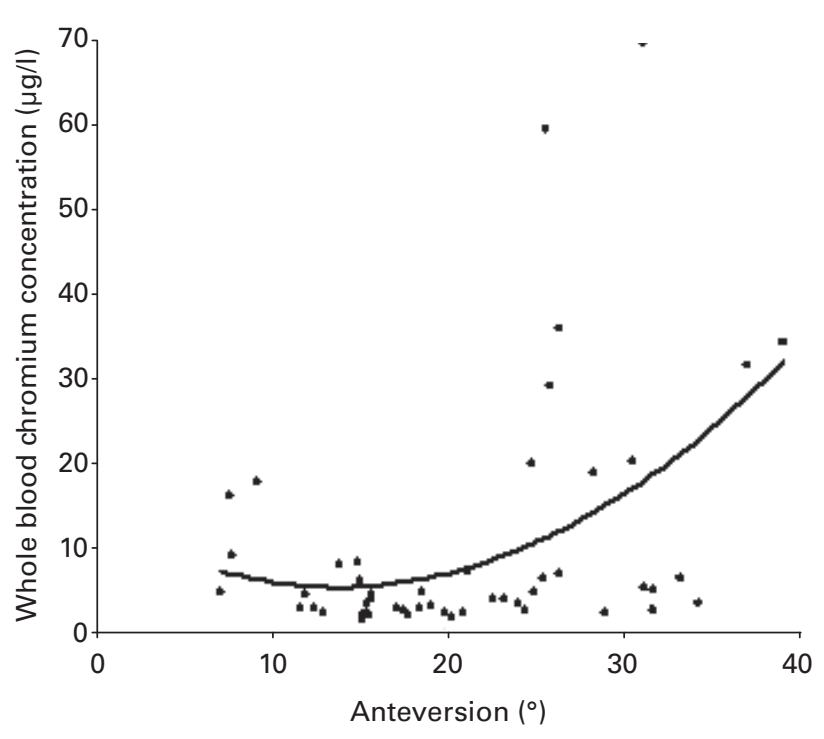

Fig. 7

Box plot showing the anteversion angle of the acetabular component versus whole blood chromium concentrations in the 55 patients with femoral implants.

Acetabular inclination was identified as the variable which best accounted for the variation seen in the concentration of metal ions. These results reflect the complex interaction between the dependent (ion concentrations) and independent (inclination/anteversion angles) variables. Most importantly, it is clear that none of the relationships were linear, thereby reducing the value of the correlation coefficient. 
Table VI. Comparison of the mean (range) metal ion concentrations ( $\mu \mathrm{g} / \mathrm{l}$ ) from previous studies in whole blood samples analysed using inductively-coupled plasma mass spectrometry

\begin{tabular}{|c|c|c|c|c|}
\hline Author/s & Implant used ${ }^{*}$ & Number of subjects & Chromium & Cobalt \\
\hline \multirow[t]{2}{*}{ Current study } & ASR (well-aligned) & 26 & $3.0(1.5$ to 8.3$)$ & $1.1(0.4 \text { to } 9.2)^{\dagger}$ \\
\hline & ASR (malaligned) & 24 & 5.9 (1.5 to 69.8$)$ & $6.7(0.4 \text { to } 271.0)^{\dagger}$ \\
\hline Daniel et $\mathrm{al}^{37}$ & $\mathrm{BHR}$ & 26 & $2.4(0.5$ to 4.9$)$ & $1.3(0.3$ to 4.8$)$ \\
\hline Venditolli et $\mathrm{al}^{38}$ & Durom & 41 & $1.3(0.4$ to 4.5$)$ & $0.6(0.3$ to 1.5$)$ \\
\hline
\end{tabular}

\section{Discussion-}

Our results identified three variables which were associated with the concentration of metal ions in whole blood, namely the size of the femoral component and the inclination and anteversion of the acetabular component. None of the relationships was straightforward. It was clear that the larger femoral implants did not 'behave' in the same way as the smaller implants. The metal ion concentrations in the blood of patients receiving a large femoral component (diameter $\geq 53 \mathrm{~mm}$ ) were significantly lower than those in patients with a smaller implant (diameter $\leq 51 \mathrm{~mm}$ ). Overall, there was no significant difference in the alignment of the component between these two groups of patients.

A logical explanation to these findings may be the development of a thicker fluid film between the articulating surfaces of larger implants. A favourable film-thickness-tosurface-roughness ratio is desirable in order to maintain low frictional forces between the articulating surfaces and to achieve full fluid-film lubrication. This ratio is known as the lambda ratio and is proportional to the femoral diameter and clearance. ${ }^{32}$ Fluid-film lubrication is enhanced by making the femoral head as large and the clearance as small as practically possible without causing jamming of the articulation. Altering these variables in this direction has been shown to reduce wear in metal-on-metal bench studies. ${ }^{14,33,34}$ However, the smaller the clearance, the more the implants are susceptible to increased wear, if the acetabular component were to be deformed during implantation. ${ }^{35,36}$ Larger acetabular components may be more resistant to deformation, thereby maintaining adequate clearance and low-wear characteristics.

Our data suggest that there is a critical size of the femoral component above which the articular surfaces are likely to be protected from the adverse effects of malalignment of the component. Daniel et $\mathrm{al}^{37}$ found lower metal ion concentrations in patients whose hips had been resurfaced with the Birmingham Hip Resurfacing (BHR) (Smith \& Nephew, London, United Kingdom) arthroplasty, and no significant difference in ion levels was observed in regard to the size of the implant. However, only two femoral sizes were examined $(50 \mathrm{~mm}$ and $54 \mathrm{~mm}$ ), the study included fewer subjects (26) and the orientation of the acetabular component was not taken into account. A comparison of the results is given in Table VI. If a well-aligned acetabular component is defined as one with $40^{\circ}$ (SD 5) of inclination and $15^{\circ}$ of anteversion the metal ion concentrations in the well-aligned ASR group are comparable with those of the BHR group. The remaining 26 patients not included in Table VI fall in between having unsatisfactory anteversion or vice versa. inclination and There are no reports of metal ion concentrations in patients with smaller BHR implants or malaligned cups.

Vendittoli et $\mathrm{al}^{38}$ found a weak inverse correlation between metal ion concentrations and femoral size, and a direct correlation with the inclination angle of the acetabular component when the Durom resurfacing arthroplasty (Zimmer, Winterthur, Switzerland) was analysed. The Durom is a sub-hemispherical resurfacing device with low clearance, similar to the ASR. In the small $(\leq 51 \mathrm{~mm}$ diameter) implant group in our study, there was a trend towards higher blood levels of metal ions with inclination angles of the acetabular component above $45^{\circ}$ and anteversion angles above $20^{\circ}$. Gross increases in anteversion and inclination may result in poor cover of the femoral component, thus decreasing the area available for generation of a fluid film. Articular surfaces which do not function under conditions of full fluid-film lubrication may be prone to more frequent surface-to-surface contact. Furthermore, if contact occurs, stresses may be transmitted over a smaller surface area. The fully hemispherical acetabular component of the BHR may protect against this phenomenon, since the available surface area is larger, thus promoting the generation of a lubricating fluid-film. However, this theoretical advantage of the BHR may be offset by the larger clearance of this implant.

Retrieval studies of metal-on-metal prostheses have confirmed that acetabular components with a high inclination angle demonstrate increased wear secondary to rim loading. ${ }^{23}$ Our results are consistent with this observation. We have also shown the importance of anteversion of the acetabular component. It is clear that increased anteversion, especially when combined with increased inclination, will lead to a reduction in the effective joint surface area. A high anteversion angle alone may present major problems in resurfacing surgery of the hip. As the headneck unit is largely restored, a decreased head-neck ratio could lead to impingement of the femoral neck on the pos- 
teroinferior part of the rim of the acetabular component during hip extension. D'Lima et $\mathrm{al}^{39}$ using a computer model of total hip replacement (although we recognise the difference in the head-neck ratio in comparison with resurfacing surgery), found that at an acetabular component anteversion of $30^{\circ}$ and femoral anteversion of between $0^{\circ}$ and $30^{\circ}$, posterior impingement could occur at hip extension of $20^{\circ}$ to $50^{\circ}$. An increase in the inclination angle further reduced the range of extension before impingement occurred. ${ }^{39}$ During the gait cycle the hip reaches extension of up to $20.4^{\circ}$ (SD 4) in young adults and of $14.3^{\circ}$ (SD 4.4) in healthy elderly individuals. ${ }^{40}$ Therefore, some patients are at a higher risk of impingement, which may culminate in microseparation, ${ }^{41,42}$ rim damage ${ }^{43}$ and possibly even subluxation. Some larger implants may be more forgiving in that respect.

Metal ions are not generated solely by mechanical wear. Another factor, which is extremely difficult to measure in vivo, is the effect of corrosion which is proportional to the surface area of the components. ${ }^{44}$ As the concentrations of metal ions in our study were lower with larger components, it would appear that mechanical wear is the predominant process driving the generation of metal ions.

Our study has some limitations. Our analysis incorporated the patients body mass index, rather than weight. It has been reported that the type of lubrication of a prosthetic joint is affected by joint loading and thus patient weight. ${ }^{32}$ Another variable which can influence lubrication, although omitted from our study for obvious practical reasons, is the viscosity of the synovial fluid. ${ }^{32}$ Other limitations of our study included the absence of pre-operative $\mathrm{Cr}$ and Co blood concentrations and information on smoking history and any dietary supplements taken by the patients. The pre-operative concentrations of metal ions are known to correlate positively with post-operative values. ${ }^{38}$ Finally, while the threedimensional orientation of the acetabular component was investigated, this was not possible for the femoral component. Although the femoral stem-shaft and neck-shaft angles were measured, the radiographs were not standardised in terms of rotation of the limb. We were also unable to measure the anteversion of the femoral component.

In conclusion, the orientation of the acetabular component in both planes appears to be critical in the generation of metal ions after ASR resurfacing arthroplasty of the hip. Inclination angles greater than $45^{\circ}$ and anteversion angles exceeding $20^{\circ}$ were associated with higher metal ion concentrations in our study. Larger acetabular components appeared to be more resistant to the effects of malalignment of the acetabular component (Table VI). The median (and maximum) values of $\mathrm{Cr}$ and Co levels associated with wellpositioned cups (acetabular compoments placed with $20^{\circ}$ or less of version and $45^{\circ}$ or less of inclination) were $3.0(8.0)$ and $1.1(6.5)$, respectively. When cups were placed beyond these boundaries, median $\mathrm{Cr}$ concentration was 5.9 (maximum value 69.8) and median Co was 6.7 (maximum value 271 ). The acetabular orientations associated with low metal ion concentrations in our study were within the limits recommended in previous studies on total hip replacement. $^{45,46}$

Based on the results of our study, we recommend that attention should be directed towards optimising the orientation of the acetabular component in order to reduce the metal ion load to which the patient is exposed. Serious consideration should be given to the development of reproducible techniques which will improve the reliability of correct alignment of the acetabular component during resurfacing arthroplasty of the hip.

Although none of the authors has received or will receive benefits for persona or professional use from a commercial party related directly or indirectly to the subject of this article, benefits have been or will be received but will be directed solely to a research fund, foundation educational institution, or other non-profit organisation with which one or more or the authors is associated.

\section{References}

1. Keegan GM, Learmonth ID, Case CP. Orthopaedic metals and their potential toxicity in the arthroplasty patient: a review of current knowledge and future strategies. J Bone Joint Surg [Br] 2007;89-B:567-73.

2. Campbell P, Urban RM, Catelas I, et al. Autopsy analysis thirty years after metalon-metal total hip replacement: a case report. J Bone Joint Surg [Am] 2003;85A:2218-22

3. Jacobs JJ, Skipor AK, Doorn PF, et al. Cobalt and chromium concentrations in patients with metal on metal total hip replacements. Clin Orthop 1996;329(Suppl):256-63.

4. Schmalzried TP, Szuszcewicz ES, Akizuki KH, Petersen TD, Amstutz HC. Factors correlating with long-term survival of McKee-Farrar total hip prosthesis. Clin Orthop 1996;329(Suppl):48-59.

5. Ladon D, Doherty A, Newson R, et al. Changes in metal levels and chromosome aberrations in the peripheral blood of patients after metal-on-metal hip arthroplasty. J Arthroplasty 2004;19 (Suppl 3):78-83.

6. Doherty AT, Howell RT, Ellis LA, et al. Increased chromosome translocations and aneuploidy in peripheral blood lymphocytes of patients having revision arthroplasty of the hip. J Bone Joint Surg [Br] 2001;83-B:1075-81.

7. Case CP. Chromosomal changes after surgery for joint replacement. J Bone Joint Surg [Br] 2001;83-B:1093-5.

8. Hart AJ, Hester T, Sinclair K, et al. The association between metal ions from hip resurfacing and reduced T-cell counts. J Bone Joint Surg [Am] 2007;87-A:28-36.

9. Willert HG, Buchhorn GH, Fayyazi A, et al. Metal-on-metal bearings and hypersensitivity in patients with artificial hip joints: a clinical and histomorphological study. J Bone Joint Surg [Am] 2005;87-A:28-36.

10. Al-Saffar N. Early clinical failure of total joint replacement in association with follicular proliferation of B-lymphocytes: a report of two cases. J Bone Joint Surg [Am] 2002;84-A:2270-3.

11. Ziaee H, Daniel J, Datta AK, Blunt S, McMinn DJW. Transplacental transfer of cobalt and chromium in patients with metal-on-metal hip arthroplasty: a controlled study. J Bone Joint Surg [Br] 2007;89-B:301-5.

12. Rieker CB, Schön R, Konrad R, et al. Influence of the clearance on in-vitro tribology of large diameter metal-on-metal articulations pertaining to resurfacing hip implants. Orthop Clin North Am 2005;36:135-42.

13. Liu F, Jin ZM, Hirt F, et al. Effect of wear of bearing surfaces on elastohydrodynamic lubrication of metal-on-metal hip implants. Proc Inst Mech Eng [H] 2005;219:319-28.

14. Smith SL, Dowson D, Goldsmith AA. The effect of femoral head diameter upon lubrication and wear of metal-on-metal total hip replacements. Proc Inst Mech Eng [H] 2001;215:161-70

15. Rieker CB, Schön R, Kottig P. Development and validation of a second-generation metal-on-metal bearing: laboratory studies and analysis of retrievals. J Arthroplasty 2004;19(Suppl 3):5-11

16. Ito $\mathbf{H}$, Minami A, Matsuno T, et al. The sphericity of the bearing surface in total hip arthroplasty. J Arthroplasty 2001;16:1024-9.

17. Chan FW, Bobyn JD, Medley JB, Krygier JJ, Tanzer M. Wear and lubrication of metal-on-metal hip implants. Clin Orthop 1999;369:10-24.

18. Schey JA. Systems view of optimizing metal on metal bearings. Clin Orthop 1996;329(Suppl):115-27. 
19. Daniel J, Ziaee H, Pradhan C, Pynsent PB, McMinn DJW. Blood and urine meta ion levels in young and active patients after Birmingham hip resurfacing arthroplasty: four-year results of a prospective longitudinal study. J Bone Joint Surg [Br] 2007;89B:169-73.

20. Case CP, Ellis L, Turner JC, Fairman B. Development of a routine method for the determination of trace metals in whole blood by magnetic sector inductively coupled plasma mass spectrometry with particular relevance to patients with total hip and knee arthroplasty. Clin Chem 2001;47:275-80.

21. Brodner W, Bitzan $\mathbf{P}$, Meisinger V, et al. Elevated serum cobalt with metal-onmetal articulating surfaces. J Bone Joint Surg [Br] 1997;79-B:316-21.

22. Brodner W, Grohs JG, Bancher-Todesca D, et al. Does the placenta inhibit the passage of chromium and cobalt after metal-on-metal total hip arthroplasty? J Arthroplasty 2004;19(Suppl 3):102-6.

23. Campbell $P$, Beaulé PE, Ebramzadeh $E$, et al. A study of implant failure in metalon-metal surface arthroplasties. Clin Orthop 2006;453:35-46.

24. Brodner W, Bitzan $P$, Meisinger V , et al. Serum cobalt levels after metal-on-meta total hip arthroplasty. J Bone Joint Surg [Am] 2003;85-A:2168-73.

25. Back D, Young DA, Shimmin AJ. How do serum cobalt levels change after metalon-metal hip resurfacing? Clin Orthop 2005;438:177-81.

26. Daniel J, Ziaee H, Pynsent PB, McMinn DJW. The validity of serum levels as a surrogate measure of systemic exposure to metal ions in hip replacement. $J$ Bone Joint Surg [Br] 2007:89-B:736-71.

27. Murray DW. The definition and measurement of acetabular orientation. J Bone Joint Surg [Br] 1993;75-B:228-32.

28. Tannast M, Langlotz U, Siebenrock K, et al. Anatomic referencing of cup orientation in total hip arthroplasty. Clin Orthop 2005;436:144-50.

29. StoeckI B, Biedermann R, Auckenthaler T, et al. Ante- and retroversion measurement of cups by EBRA. J Bone Joint Surg [Br] 2001;83-B(Suppl II):179.

30. Ochsner $\mathbf{P E}$. Measurement of the acetabular migration by using standard AP radiographs (EBRA): technique, results and practical application in clinical work. J Bone Joint Surg [Br] 1998;80-B(Suppl I):33.

31. Amstutz HC, Thomas BJ, Jinnah R, et al. Treatment of primary osteoarthritis of the hip: a comparison of total joint and surface replacement arthroplasty. $J$ Bone Joint Surg [Am] 1984;66-A:228-41

32. Joyce TJ. Examination of failed ex vivo metal-on-metal metatarsophalangeal prosthesis and comparison with theoretically determined lubrication regimens. Wear 2007;263:1050-4.

33. Dowson D. New joints for the millennium: wear control in total replacement hip joints. Proc Inst Mech Eng [H] 2001;215:335-58.
34. Smith SL, Dowson D, Goldsmith AAJ. The effect of diametral clearances, motion and loading cycles upon lubrication of metal-on-metal hip replacements. Proc Inst Mech Eng [C] 2001;215:1-5.

35. Jin ZM, Meakins S, Morlock MM, et al. Deformation of press-fitted metallic resurfacing cups. Part 1: experimental simulation. Proc Inst Mech Eng (H) 2006;220:299-309

36. Yew A, Jin ZM, Donn A, Morlock MM, Isaac G. Deformation of press-fitted metallic resurfacing cups. Part 2: finite element simulation. Proc Inst Mech Eng (H) 2006;220:311-19

37. Daniel J, Ziaee H, Salama A, Pradhan C, McMinn DJW. The effect of the diameter of metal-on-metal bearings on systemic exposure to cobalt and chromium. $J$ Bone Joint Surg [Br] 2006;88-B:443-8.

38. Vendittoli PA, Mottard S, Roy AG, Dupont C, Lavigne M. Chromium and cobalt ion release following the Durom high carbon content, forged metal-on-metal surface replacement of the hip. J Bone Joint Surg [Br] 2007;89-B:441-8.

39. D'Lima DD, Urquhart AG, Buehler KO, Walker RH, Colwell CW Jr. The effect of the orientation of the acetabular and femoral components on the range of motion of the hip at different head-neck ratios. J Bone Joint Surg [Am] 2000;82-A:315-21.

40. Kerrigan DC, Lee LW, Collins JJ, O'Riley PO, Lipsitz LA. Reduced hip extension during walking: healthy elderly and fallers versus young adults. Arch Phys Med Rehabil 2001;82:26-30.

41. Lombardi AV, Mallory TH, Dennis DA, et al. An in vivo determination of total hip arthroplasty pistoning during activity. J Arthroplasty 2000;15:702-9.

42. Nevelos J, Ingham E, Doyle C, et al. Microseparation of the centers of aluminalumina artificial hip joints during simulator testing produces clinically relevant wear rates and patterns. J Arthroplasty 2000;15:793-5.

43. Williams S, Stewart TD, Ingham E, Stone MH, Fisher J. Metal-on-metal bearing wear with different swing phase loads. J Biomed Mater Res B Appl Biomater 2004;70:233-9.

44. Jacobs JJ, Gilbert JL, Urban RM. Corrosion of metal orthopaedic implants. J Bone Joint Surg [Am] 1998:80-A:268-82.

45. Biedermann $\mathbf{R}$, Tonin A, Krismer $\mathbf{M}$, et al. Reducing the risk of dislocation after total hip arthroplasty: the effect of orientation of the acetabular component. J Bone Joint Surg [Br] 2005;87-B:762-9.

46. Lewinnek GE, Lewis JL, Tarr R, Compere CL, Zimmerman JR. Dislocations after total hip replacement arthroplasties. J Bone Joint Surg [Am] 1978;60-A:21720. 